\title{
Claim success, but blame the bot? User reactions to service failure and recovery in interactions with humanoid service robots
}

\author{
Nika Mozafari \\ University of Goettingen \\ nika.mozafari@ \\ wiwi.uni-goettingen.de
}

\author{
Melanie Schwede \\ University of Goettingen \\ melanie.schwede@ \\ wiwi.uni-goettingen.de
}

\author{
Maik Hammerschmidt \\ University of Goettingen \\ maik.hammerschmidt@ \\ wiwi.uni-goettingen.de
}

\author{
Welf H. Weiger \\ Alfaisal University \\ wweiger@ \\ $\underline{\text { alfaisal.edu }}$
}

\begin{abstract}
Service robots are changing the nature of service delivery in the digital economy. However, frequently occurring service failures represent a great challenge to achieve service robot acceptance. To understand how different service outcomes in interactions with service robots affect usage intentions, this research investigates (1) how users attribute failures committed by humanoid service robots and (2) whether responsibility attribution varies depending on service robot design. In a 3 (success vs. failure vs. failure with recovery) $\times 2$ (warm vs. competent service robot design) between-subject online experiment, this research finds evidence for the self-serving bias in a service robot context, that is, attributing successes to oneself, but blaming others for failures. This effect emerges independently from service robot design. Furthermore, recovery through human intervention can mitigate consequences of failure only for robots with warm design. The authors discuss consequences for applications of humanoid service robots and implications for further research.
\end{abstract}

\section{Introduction}

Over the past couple of years, artificial intelligence (AI) based assistants have been vigorously changing the service landscape [1]. A key manifestation of AI-based assistants are service robots, which are deployed in the service frontline to interact with users in order to deliver services [2]. Applications range from retail [3], over hotel and restaurants $[4,5]$, to hospitality and healthcare services [6, 7]. Especially the latter have gained importance as the Covid-19 pandemic transforms the digital economy, where service delivery becomes increasingly technology-mediated.

Service robots are able to take on tasks of high cognitive-analytical complexity [2] and are currently taking great leaps towards performing tasks that require high empathetic intelligence [8]. However, while organizations invest in creating effective human-robot interactions (HRI), reality proves that service robots are oftentimes prone to failure, which in turn results in lower usage intentions [9]. To better understand how users react to failures, our research investigates how users assign responsibility for service outcomes. Service research shows that users who feel in control and therefore responsible for service outcomes are more satisfied with the service experience [10]. However, in the context of service robots, the examination of responsibility attribution (i.e., whether users think they are responsible for creating the service outcome), is still limited.

Interestingly, service research has long recognized that fully eliminating failures from service interactions is "an insurmountable task" [11, p. 153]. While organizations need to invest efforts in improving service robots to reduce failures, it becomes apparent that it will always be necessary to find ways of dealing with negative user reactions after service failures. Overall, research on failures in interactions with service robots is limited [9]. In particular, further research on how to effectively recover from service failures is needed [5], and to our knowledge there is no prior research on effects of recovery on responsibility attribution in HRI. Therefore, we aim to answer following research question:

$R Q_{1}$ : How do service failure and service recovery affect responsibility attribution in interactions with service robots?

Moreover, prior research that has investigated user attributions of service robot failures has dominantly focused on comparing failures committed by service robots to failures committed by humans [e.g., 4, 12]. However, whether effects of service failure on responsibility attributions differ depending on service robot design remains largely unexamined. This is 
startling, because previous HRI research has shown that different robot designs can consequently lead to different user responses [13]. Prior research on repercussions of service robot failures points out that human-like features of service robots could change responsibility attribution and calls for further research [14]. More specifically, the two central dimensions of human social cognition, which are warmth and competence [15], promise to be effective in explaining user reactions to service robots [13]. Therefore, we examine how warm and competent robot design affect user attributions after service failure and recovery. Hence, we ask:

$R Q_{2}$ : How does warm vs. competent service robot design impact the relationship between service outcome and responsibility attributions?

Finally, prior studies that have investigated service failure have merely focused on examining user attributions. Notably, existing research has not addressed how these attributions affect subsequent user behavior [16]. However, insights on behavioral outcomes are needed to offer organizations actionable implications. Therefore, we further pose following research question:

$R Q_{3}$ : How do responsibility attributions of service outcomes in interactions with service robots affect usage intention?

In answering these three research questions, our study contributes to research on service delivery with robots in several ways. First, we contribute to research on attributional thinking by providing support for the existence of a self-serving bias (i.e., claiming success to oneself, but blaming external circumstances for failures) in a service robot context. Second, by investigating repercussions of not only failure, but further service recovery, we show that depending on robot design, recovery through human intervention can mitigate external attribution and instead shift responsibility attribution towards internal attribution. Third, by applying concepts from social cognition, we demonstrate that robot design affects attributional thinking. Specifically, users attribute responsibility more internally, if the outcome was caused by a service robot with warm (instead of competent) design. Finally, by including usage intention, our research provides insights on user reactions beyond psychological mechanisms. Results show that usage intentions increase with more internal (rather than external) responsibility attribution.

\section{Related work on service robot failures and recovery}

Service robots are "system-based autonomous and adaptable interfaces that interact, communicate and deliver service to an organization's customers" [2, p. 909]. Current research examines the acceptance of service robots $[2,17,18]$, the design of service robots [19-22], the impact of service robots on the userorganization relationship [23, 24], failures in HRI [4, 9, 14] and user reaction to such failures [5, 25].

We define service failures as situations, in which the service delivery by the robot does not result in the desired service outcome [26]. Previous service studies on AI-based assistants considered, for instance, the influence of text-based vs. embodied interfaces on service failures [27], the influence of service failures on humanness perceptions [28], the attribution of responsibility [14] and stability after a service failure [4], and user reactions to different failure types [5]. These studies were able to show that it is important to understand how service robot failures affect users emotionally and cognitively. Users attribute service failures differently to service robots and organizations [4], users perceive bots after a service failure as less human [28], and service failure types influence social perceptions of humanoid vs. non-humanoid service robots [5]. However, if the bot has a human appearance, then it is more likely that users will forgive a failure [27]. Furthermore, previous studies that have examined behavioral components additionally find, for example, that service failures lead to dissatisfaction or negative service evaluations, which is detrimental for organizations [5, 28, 29].

Service research has long established that service failures are the main cause of user switching behavior [30]. In order to retain users, organizations need to assess which recovery strategy is most effective in interactions with service robots [9]. Prior studies that have investigated different recovery strategies in interactions with service robots have thus far mainly focused on robot-initiated actions [26, 31]. Most commonly, research has examined the effectiveness of apologies and explanations [5, 9]. Service literature recommends these two strategies [32] because they effectively appease the user in the first step [5, 33]. These strategies act as informative help [34]. However, previous studies have shown that a recovery that provides immediate assistance received a better service evaluation than informative recovery strategies [29]. Therefore, recently, researchers and organizations are increasingly focusing on solving the problem through human handover $[5,9,31]$. This recovery strategy promises to be more effective in repairing impaired reusage intentions, because it can improve user experience 
through quick resolution [35] and can therefore mitigate dissatisfaction with the required service [5]. These findings indicate that users seek to have the problem itself solved in service situations [36].

\section{Theoretical background}

\subsection{Responsibility attribution}

When service failures occur, users seek to explain this circumstance [37]. Attribution research considers "how people arrive at causal inferences, what sort of inferences they make, and what the consequences of these inferences are" [38, p. 548]. Therefore, attribution theory allows us to analyze how users assign blame when a service failure happens [39]. In attribution theory, this refers to the term responsibility attribution, which describes the perceived cause of the service outcome [4, 38, 40]. The user can attribute an outcome, whether failure or success, internally, to themselves, or externally, to an organization, service robot, employee, etc. [4, 37, 41]. In recent years, studies examined attribution theory in the context of (self-serving) technology [42] and service robots [4, 16, 41]. Existing research shows that the theory is suitable to understand responsibility attribution of users towards new AI-based technology [14, 41]. Previous studies in HRI have examined attributional thoughts in the context of different service outcomes like failure vs. success [4], with different frontline agents oftentimes robot vs. human [4, 12, 14], technology's autonomy and behavioral control [16], different user attributions like robot or organization responsibility [14] and relative status of the robot [41].

A tenet of attribution theory is that attributions are prone to biases - the most prominent bias is the selfserving bias, which describes the tendency of users to explain negative outcomes externally and attribute positive outcomes to their own abilities (internally) [43, 44]. As studies show, this bias can also be applied to the technology context $[41,44]$. Following the self-serving bias, the attribution of responsibility depends on the service outcome. Therefore, we hypothesize the following in the context of service robots:

$H_{l a}$ : The user is more likely to attribute responsibility externally if the service outcome is a failure (vs. success).

Prior work on service recovery has shown that recovery efforts are successful in attenuating negative user reactions after failure [e.g., 5, 29]. However, whether this applies to responsibility attribution is unclear. Previous research on recovery through immediate and active assistance shows that users evaluate the service more positively [29]. Users should therefore blame the service robot less and are more likely to forgive it because of the immediate assistance provided. Furthermore, the external responsibility attribution in response to failures is a result of maintaining a positive self-image of oneself, or a "selfprotection strategy" [45, p. 23]. Through recovery however, the need to self-protect should not be as prominent because the failure will be resolved. Furthermore, negative (i.e., external) attributions after failures are a result of a lack of recovery. However, when organizations provide recovery and thus change the service outcome to a favorable one, external attributions will be reduced [25]. Hence, we assume that service recovery will minimize the external attribution of blame. Therefore, we hypothesize:

$H_{1 b}$ : If a service failure is recovered, external responsibility attribution is mitigated.

Finally, attributions of service outcomes determine the perception of service quality and behavioral reactions such as (dis)satisfaction or service loyalty [10], which should be reflected in the intention to use the service robot. As services are jointly produced by organization and user, if users attribute the responsibility of a service outcome to themselves, they feel like they have contributed to the service outcome [10]. Therefore, we assume that users who feel in control of a service outcome are more likely to use the service robot again in the future. This leads to the following hypothesis:

$\mathrm{H}_{2}$ : Internal attribution of responsibility has a positive effect on the intention to use the service robot.

\subsection{Social perceptions of service robots}

Prior work suggests that user reactions to service robots depend on their design. More specifically, organizations humanize service robots because this promises higher usage intention [46]. This happens because with an increasingly human-like interface, users tend to perceive and treat robots as social beings $[44,47$, 48].

In social psychology, social perception distinguishes between the two universal dimensions of warmth and competence [15]. These two dimensions are based on the Stereotype Content Model (SCM) and are closely related to other important constructs of social perception $[15,49]$. The dimension of warmth describes whether the social counterpart intends something good and is often described with characteristics such as friendliness and trustworthiness $[15,50]$. The dimension of competence encompasses whether the social 
counterpart has the ability to accomplish certain purposes and is associated with intelligence and capability $[15,50]$. Prior research shows that these two dimensions of social perception are also relevant in the case of humanoid service robots [5].

In previous research, however, it is still controversial which dimension is more important, because it depends on various factors such as the service context or the user segment [51]. While warmth perceptions support relational outcomes such as userorganization identification, competence perceptions have a positive effect on transactional outcomes of the user-organization relationship [51].

In robot design, features like a friendly face can increase perceived warmth [13], which creates a certain relatedness in the interaction. Human features are not necessary to elicit competence perceptions, they are instead fostered through functional elements [52]. Accordingly, both warmth and competence perceptions seem to be positively related to service robot acceptance [2]. Notably, previous findings suggest that higher warmth perceptions are oftentimes associated with lower competence perceptions [53]. This means that if service robot design fosters warmth perceptions, competence perceptions might be mitigated, and vice versa.

As stated above, high competence perceptions are associated with greater intelligence and ability. Therefore, users expect service robots designed to elicit competence perceptions to be capable of providing a certain outcome. As a consequence, the robot will be seen as more responsible for service outcomes. However, for service robots with warm design, users do not ascribe them the capability to achieve an outcome to the same extent. Instead, they should feel the robot has produced the service outcome only with the help of the user's efforts. Therefore, service robot design affects user attribution as follows:

$H_{3}$ : The user is more likely to attribute responsibility internally for service robots with warm (vs. competent) design.

As noted in $\mathrm{H}_{1 \mathrm{a}}$, we assume that service failures in interactions with service robots trigger the self-serving bias. In interactions between humans, attributional research has shown that the bias emerges between strangers. However, and interestingly, the bias is less pronounced or even non-existent if the persons involved are friends [54]. Warm robot design intends to elicit feelings of friendliness and relatedness [13], which should be comparable to feelings in encounters between friends. Accordingly, we assume that warm robot design will mitigate external responsibility attribution. Therefore:

$H_{4 a}$ : The effect of service failure on external responsibility attribution is mitigated, if service robots have a warm (vs. competent) design.

As established in $\mathrm{H}_{1 \mathrm{~b}}$, service recovery minimizes the effect of failure on external attribution. We assume that the magnitude of this effect is dependent on service robot design. More specifically, we assume that recovery efforts will be more successful in mitigating external attribution for a service robot with warm design than for a service robot with competent design. When interacting with users on a personal, emotional level, warm robot design increases trust, the likelihood of forgiving a service failure and also reduces complaining intentions [55]. This suggests that users should be more forgiving towards service robots with warm design, because they perceive them as being helpful and caring. Users seek to maintain this friend-like relationship by forgiving failures [13]. In addition, the SCM addresses the fact that individuals feel pity and sympathy for others that they perceive as highly warm and less competent [15] and are therefore more likely to forgive the service bot with a warm design. Therefore, after service recovery through immediate assistance, users show more forgiveness towards service robots with warm design and should be more content to take part of the responsibility onto themselves. Hence, we hypothesize:

$H_{4 b}$ : The mitigating effect of recovery on external responsibility attributions is more prominent for service robots with warm (vs. competent) design.

Figure 1 illustrates the research framework as well as the hypotheses.

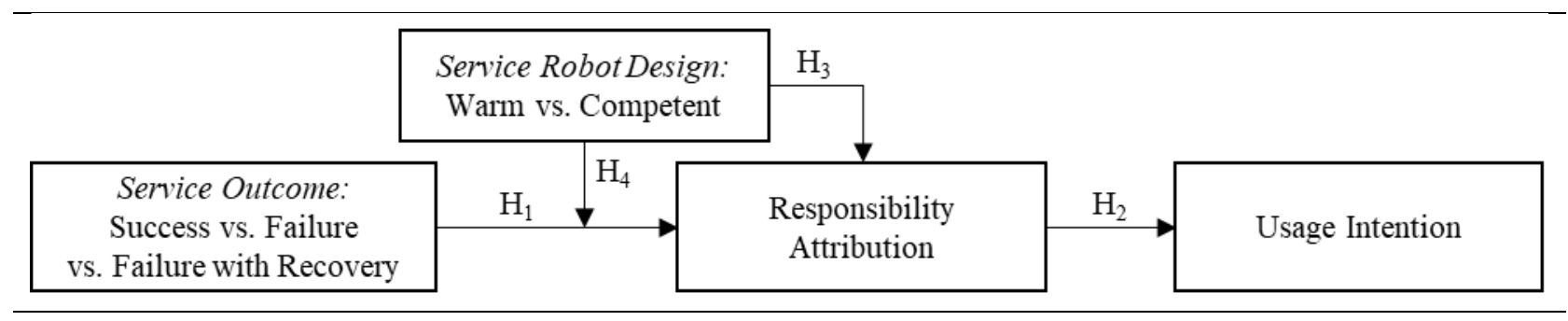

Figure 1. Research framework 


\section{Study}

\subsection{Design and sample}

To test our hypotheses, we conducted a 3 (service outcome: success vs. failure vs. failure with recovery) $\times$ 2 (service robot design: warm vs. competent) betweensubject online experiment. We recruited participants of a European university by using distribution lists and social media. After the survey, participants could take part in an optional raffle of online shopping vouchers. We chose a scenario-based approach to ensure that the interactions were identical, with the exception of the respective manipulations. In doing so, we could control for confounding influences to achieve high internal validity. After a brief introduction to the survey, we instructed participants to imagine they were feeling ill and wanted to seek medical assistance. When they arrived at the doctor's office, they were greeted by a humanoid service robot. Participants faced the humanoid service robot as a static image. We chose a medical context for the setting of our experiment because recently, against the background of the Covid19 pandemic, the medical sector has experienced a surge in service robot applications [56].

At the beginning of the experiment, the survey tool randomly assigned the participants to one of the six experimental groups. In both service robot design scenarios, participants saw a version of the service robot Cruzr by Ubtech Robotics. Not only did organizations increasingly employ Cruzr during the Covid-19 pandemic [57], but prior empirical studies also used it as a focal object [58]. Both versions of the service robot design include a humanoid form, in that the robot has arms and a torso. For the warm service robot design, we chose a humanoid face, because prior studies show that human-like features foster perceptions of human warmth through purporting social capabilities [5]. In contrast, the face of the competent service robot merely consisted of a display with no further human-like features. This was done to make the robot appear more machine-like, and consequently less warm and more efficient. Figure 2 depicts the two different service robot designs.

Beyond the robots' appearances, we manipulated warmth and competence perceptions through their greetings in the beginning of the scenarios. The introduction of the service robot with warm design was "Nice to see you, I am happy to help you. Please tell me what ails you". This was done to elicit perceptions of kindness and empathy. The service robot with competent design introduced itself with the words "Thanks to the use of the latest technology, I can be of great help to you. Please tell me about your symptoms". After this introduction we asked participants to rate their competence and warmth perceptions on 7-point Likert scales ranging from $1=$ strongly disagree to $7=$ strongly agree. We assessed both variables with five items each (Perceived competence: "The robot is competent, confident / intelligent / knowledgeable / efficient", $\alpha=0.89$; perceived warmth: "The robot was warm / good-natured / sincere / friendly / trustworthy.", $\alpha=0.86$; adapted from [49]).

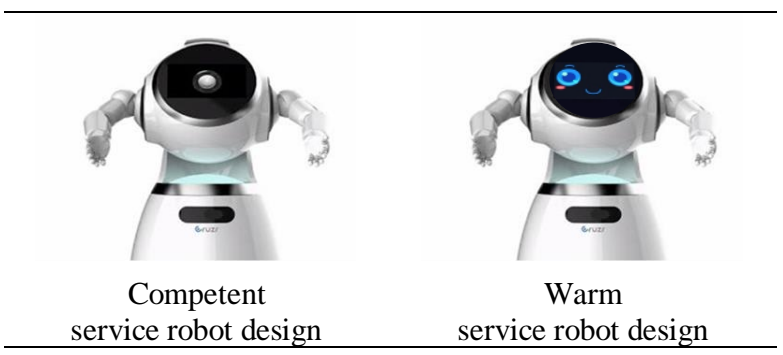

Figure 2. Service robot design manipulation

Next, we instructed to the participants to imagine that they described their symptoms to the service robot. In the success scenario, the robot would give the participant their diagnosis, while in the service failure scenario the robot is unable to give a diagnosis. In the recovery scenario, the service robot informed the participants that they will be transferred to a human physician, who finally gives a diagnosis. We chose human handover as recovery strategy because prior work suggests it is an effective means of mitigating negative user responses after failures [31]. The diagnosis given in the recovery scenario was identical to the diagnosis in the service success scenario. We delivered all information including the greeting by the service robot via reported speech, for example „The robot tells you that your symptoms point to a flu-like infection".

After the experiment, participants answered manipulation checks on service outcome ("The robot could solve my service inquiry"; [59]) as well as service recovery ("A solution was provided to my problem"; [59]. We collected the measure on responsibility attribution ("The responsibility for the outcome of the service interaction lies (1) outside of me / (7) inside of me"; [60]) as well as usage intention ("If given the chance, I plan to use the service robot in the near future", "If given the chance, I think I'll use the service robot in the near future", $\alpha=0.96$; [61]). The survey closed with a question on prior experience with service robots ("I am experienced in interacting with service robots"), demographics and attention checks. Except for demographics, we measured all items on 7-point Likert scales anchored by $1=$ strongly disagree to $7=$ strongly agree, if not stated otherwise.

The initial sample consisted of 349 participants. We discarded those who did not correctly recall and identify 
how the service robot looked like (23 participants) and those who self-reported that they did not fill out the survey conscientiously (1 participant) from further analyses. Therefore, the final sample comprises 325 participants $\left(75 \%\right.$ female, $M_{\text {age }}=30$ years $)$, which are approximately evenly distributed across the six scenarios. Overall, the participants perceived the scenarios as realistic ("The presented scenario was realistic", [62], $M=4.8, S D=1.9)$. There were no significant differences in realism perceptions across scenarios. Furthermore, there were no significant differences in distribution of age, gender and prior experience with service robots across scenarios (all $p>0.1)$.

\subsection{Results}

The manipulation checks for perceived competence and warmth show that the service robot with competent design is perceived as significantly more competent than the service robot with warm design $\left(M_{\text {competent }}=4.53\right.$, $\left.S D=1.29 ; M_{\text {warm }}=4.18, S D=1.38 ; t=2.36, p<0.01\right)$. Furthermore, the service robot with warm design is perceived as significantly warmer than the service robot with competent design $\left(M_{\text {competent }}=3.79, S D=1.35\right.$; $\left.M_{\text {warm }}=4.35, S D=1.35 ; t=-3.39, p<0.001\right)$. This shows that manipulation of service robot design was successful. Interestingly, these results provide evidence for the fact that higher warmth perceptions are associated with lower competence perceptions and vice versa. Furthermore, the manipulation checks for perceived service outcome $\left(M_{\text {success }}=4.36, S D=1.68\right.$; $\left.M_{\text {failure }}=1.55, S D=1.23 ; t=14.10, p<0.001\right)$ and service recovery $\left(M_{\text {failure }}=1.67, S D=1.34 ; M_{\text {recovery }}=\right.$ 2.06, $S D=1.74 ; t=-1.84, p<0.05)$ were also successful.

To test hypotheses $\mathrm{H}_{1}, \mathrm{H}_{3}$ and $\mathrm{H}_{4}$, we conducted an analysis of variance (ANOVA) with responsibility attribution as dependent variable and service outcome, service robot design as well as their interaction as independent variables. ANOVA results show a significant main effect of service outcome on responsibility attribution $(F(2,319)=17.51, p<0.001)$. Planned contrasts of predictive margins show that responsibility for service failure is attributed significantly more externally than for service success $\left(M_{\text {success }}=3.95, S E=0.16 ; M_{\text {failure }}=2.61, S E=0.16\right.$; $t=-5.89, p<0.001$ ), which provides support for $\mathrm{H}_{1 \mathrm{a}}$ and the existence of the self-serving bias in a service robot context. As assumed, if the service failure is recovered, the self-serving bias can be mitigated successfully $\left(M_{\text {recovery }}=3.14, S E=0.16 ; t=2.38, p<0.05\right)$, which further provides support for $\mathrm{H}_{1 \mathrm{~b}}$. Furthermore, ANOVA results show a significant main effect of service robot design on responsibility attribution $(F(1,319)=5.30$, $p<0.05)$. More precisely, outcomes are attributed significantly more internally for robots with warm than for robots with competent design $\left(M_{\text {competent }}=3.02\right.$, $\left.S E=0.14 ; M_{\text {warm }}=3.45, S E=0.13 ; t=2.3, p<0.05\right)$, which provides support for $\mathrm{H}_{3}$.

Finally, to analyze the interaction effect, we rely on planned contrasts. Figure 3 shows an overview of the interaction effect. Inconsistent with $\mathrm{H}_{4 \mathrm{a}}$, the effect of failure on external attribution is not less severe for warm than for competent service robot design, because there is no significant difference in the emergence of the selfserving bias between service robot design manipulations $\left(\Delta M_{\text {competent } \times \text { failure }}=-1.27, \mathrm{SE}=0.34 ; \Delta M_{\text {warm } \times \text { failure }}=\right.$ $-1.41, \mathrm{SE}=0.30)$. However, and in accord with $\mathrm{H}_{4 \mathrm{~b}}$, the mitigating effect of recovery is more prominent for the warm than for the competent service robot design. $\left(\Delta M_{\text {competent } \times \text { recovery }}=0.41, \mathrm{SE}=0.34 ; \Delta M_{\text {warm } \times \text { recovery }}=\right.$ $0.65, \mathrm{SE}=0.31)$. Notably, planned contrasts show that the mitigating effect of recovery is significant for warm service robot design $(t=2.11, p<0.05)$, but insignificant for competent service robot design $(t=1.27, p>0.1)$. This implies that the self-serving bias cannot be attenuated through service recovery, if service robot design is focused on competence.

To test the effect postulated in $\mathrm{H}_{2}$, we conducted regression analysis with usage intention as dependent variable and responsibility attribution as independent variable. There is a significant positive effect of (internal) responsibility attribution on usage intention $(\beta=0.18, S E=0.05 ; t=3.41, p<0.01)$, which confirms $\mathrm{H}_{2}$.

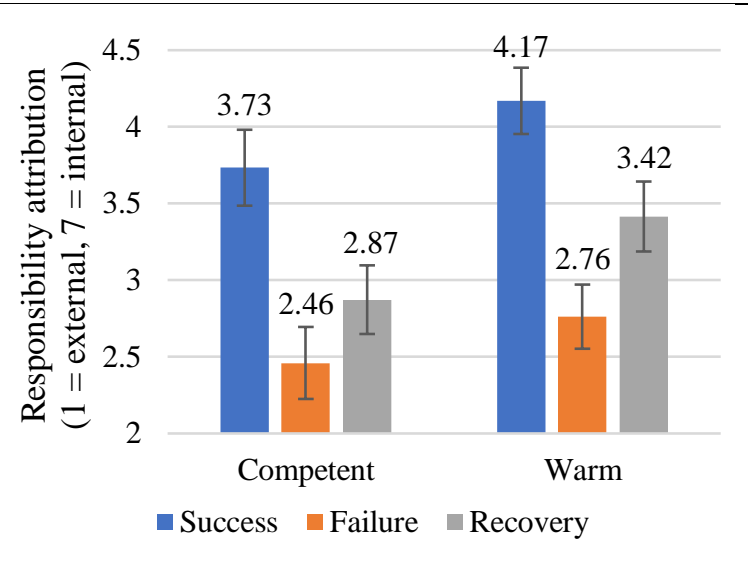

\section{Figure 3. Predictive margins for responsibility attribution}

\section{Discussion and implications}

The results provide evidence for the self-serving bias in a service robot context: While users claim responsibility for successes, they shift blame for failure 
away from themselves. The former implies that users believe they contributed to the successful outcome, in our case by communicating their symptoms successfully. The latter however suggests that in case of a service failure, users deem the service robot responsible, in that the robot must not have been able to understand the communicated symptoms. This bias emerges in order to cope with situations that disfavor the user's self-perceptions [45]. Consequentially, if users attribute responsibility for an outcome internally, usage intentions increase. However, if users attribute an outcome externally, usage intentions decrease. This happens because users like to feel in control of a situation, which is in line with findings from prior research on traditional service interactions [10]. Interestingly, through a successful recovery that immediately provides a successful outcome, the responsibility attribution shifts towards internal attribution, away from external attribution, which is predominantly in line with theory [36]. Therefore, if a service failure is recovered, the negative effect of failure on usage intention can be indirectly mitigated through a less external attribution of responsibility.

Moreover, users attribute outcomes caused by service robots with warm design more internally, while they attribute outcomes caused by service robots with competent design more externally. On the one hand, this implies that users perceive robots with competent design as more capable and in charge of their actions, thus more responsible for outcomes, which is consistent with existing theory $[15,50]$. On the other hand, users perceive outcomes in interactions with robots with warm design as being created through the effort of the user, e.g. more as a result of a co-creation process [63].

Furthermore, when taking a closer look at interactions of service outcome and service robot design, it becomes apparent that overall, the self-serving bias exists independently from robot design. The main effect of robot design described above is therefore outweighed by service failure. Contrary to our hypothesis, the effect of failure on external attribution was not less distinct for robots with warm design. Attributional research suggests that the self-serving bias does not emerge in interactions between friends [54]. We assumed that through warm robot design, a similar result would be achieved. However, this was not the case, presumably because the brief interaction with the service robot was not able to elicit the same feelings of closeness that users feel in interactions with friends.

We further find that external attribution of responsibility through failure can only be mitigated through service recovery if service robot design focuses on warmth. We assume this is because users are more forgiving towards a robot they perceive as friendly and good-natured [55]. Therefore, while for competent robot design, after service recovery users still deem the robots responsible to the same extent as without recovery, for warm robot design this is not the case. Instead, through recovery in response to failure committed by a service robot with warm design, users tend to take part of the blame onto themselves.

Overall, these findings contribute to research on attributions of different service outcomes in a service robot context [64]. In summary, the findings have several implications for organizations. Through external responsibility attribution, service failures drastically diminish usage intentions. This effect is so severe that design considerations seem to become dispensable in failure situations. However, and interestingly, if failure is recovered, users are less likely to blame external circumstances and therefore more likely to use the robot again, if the robot design focuses on warmth. Ideally, organizations should continue striving for failure-free service interactions, while simultaneously working out recovery strategies that alleviate the cost of service failures.

\section{Limitations and future research}

The present study is not free of limitations, which open up avenues for further research. When considering attributional processes in response to different service outcomes, our work focuses on responsibility attribution. These attributions can be made internally or externally. Traditionally, attribution theory investigates three types of attributions: locus of causality, controllability and stability [37]. Extant studies have combined the former two to the dimension of responsibility attribution [4], which is the variable examined here. Furthermore, we did not include stability perceptions in our framework, as prior work has found that stability attributions are of less relevance in failure situations $[14,65]$. For a more nuanced overview of how user attributions explain the effect of different service failures and robot designs on usage intentions, future studies should consider including all dimensions as explanatory mechanisms.

Second, this study focuses on the assertion of the self-serving bias, which compares internal vs. external responsibility attributions. However, from our results it remains unclear, whether external attributions refer to the robot or the organization, or even other causes. Future work should examine this by not only measuring internal vs. external attribution, but further refine to what "external" refers.

Next, we considered warmth and competence dimensions for service robot design. The manipulation checks on perceived competence and warmth suggest that the two dimensions are mutually exclusive, at least as a result of our operationalization. However, in prior 
work, traits that stimulate warmth perceptions did not interfere with competence perceptions [5]. Existing research has discussed under which circumstances the dimensions co-occur or not [53], however, this question remains unanswered in service robot research. With regards to the setting of our study, prior literature suggests that both warmth and competence perceptions are relevant for robot acceptance in a medical context [66]. Future studies should consider manipulating different configurations and combinations of warmth and competence.

Moreover, the physical appearance of robots has been demonstrated to be vital to the perception and evaluation of robots [46]. In this study however, neither warm nor competent service robot design could buffer the negative effects of failure. Therefore, future research should further investigate different aspects of humanlike service robot design in interactions with different service outcomes. Altogether, it becomes apparent that the effect of service failure mostly outweighs design considerations. For firms, this implies that investing effort in recovery strategies is of great relevance. In our study, it has been shown that the human intervention mitigates consequences for a robot with a warm design. Further studies could explore additional recovery strategies, such as recovery through the respective (or even another) robot.

Finally, our studies relied on descriptive scenarios with pictures of service robots, instead of a real service interaction. We did this to be able to control for confounding influences and to assure that the interactions are identical except for the respective manipulations. As a consequence, external validity may have been hampered [67]. To address this, future studies should examine real-life interactions between users and service robots.

\section{Conclusion}

Despite the fact that AI-based assistants like service robots become increasingly capable of handling deeply complex tasks, they are not free of failures. Therefore, understanding the impact of failures and creating strategies to recover from them will remain of relevance. The goal of the present work was to examine how users attribute responsibility for different service outcomes. The findings shed light on the fact that users tend to claim responsibility for successes, however blame external circumstances for service failures. When assessing different service robot designs, our results suggest that service failures overshadow design considerations. However, through recovery, external responsibility attribution can be mitigated for service robots with warm design. At last, we demonstrate that shifting responsibility towards internal attribution fosters usage intentions.

\section{References}

[1] Rust, R.T. and M.-H. Huang, "The Service Revolution and the Transformation of Marketing Science", Marketing Science, 33(2), 2014, pp. 206-221.

[2] Wirtz, J., P.G. Patterson, W.H. Kunz, T. Gruber, V.N. Lu, S. Paluch, and A. Martins, "Brave new world: service robots in the frontline", Journal of Service Management, 29(5), 2018, pp. 907-931.

[3] Meyer, P., J.M. Jonas, and A. Roth, "Frontline Employees' Acceptance of and Resistance to Service Robots in Stationary Retail - An Exploratory Interview Study", Journal of Service Management Research, 4(1), 2020, pp. 21-34.

[4] Belanche, D., L.V. Casaló, C. Flavián, and J. Schepers, "Robots or frontline employees? Exploring customers' attributions of responsibility and stability after service failure or success", Journal of Service Management, 31(2), 2020, pp. 267-289.

[5] Choi, S., A.S. Mattila, and L.E. Bolton, "To Err Is Human (-oid): How Do Consumers React to Robot Service Failure and Recovery?", Journal of Service Research, 6(3), 2020, 1-18.

[6] Yoganathan, V., V.-S. Osburg, W. H. Kunz, and W. Toporowski, "Check-in at the Robo-desk: Effects of automated social presence on social cognition and service implications", Tourism Management, 85, 2021, 104309.

[7] Čaić, M., G. Odekerken-Schröder, and D. Mahr, "Service robots: value co-creation and co-destruction in elderly care networks", Journal of Service Management, 29(2), 2018, pp. 178-205.

[8] Huang, M.-H. and R.T. Rust, "Artificial Intelligence in Service", Journal of Service Research, 21(2), 2018, pp. 155172.

[9] Honig, S. and T. Oron-Gilad, "Understanding and Resolving Failures in Human-Robot Interaction: Literature Review and Model Development", Frontiers in psychology, 9, 2018, pp. 861-882.

[10] van Raaij, W.F. and A.T. Pruyn, "Customer control and evaluation of service validity and reliability", Psychology and Marketing, 15(8), 1998, pp. 811-832.

[11] Webster, C. and D.S. Sundaram, "Service consumption criticality in failure recovery", Journal of Business Research, 41(2), 1998, pp. 153-159.

[12] Merkle, M., "Customer Responses to Service Robots Comparing Human-Robot Interaction with Human-Human Interaction", in Proceedings of the 52 ${ }^{\text {nd }}$ Hawaii International Conference on System Sciences, Hawaii, USA, 2019.

[13] van Doorn, J., M. Mende, S.M. Noble, J. Hulland, A.L. Ostrom, D. Grewal, and J.A. Petersen, "Domo Arigato Mr. Roboto", Journal of Service Research, 20(1), 2017, pp. 43-58. 
[14] Leo, X. and Y.E. Huh, "Who gets the blame for service failures? Attribution of responsibility toward robot versus human service providers and service firms", Computers in Human Behavior, 113, 2020, 106520.

[15] Fiske, S.T., A.J.C. Cuddy, and P. Glick, "Universal dimensions of social cognition: warmth and competence", Trends in cognitive sciences, 11(2), 2007, pp. 77-83.

[16] Jörling, M., R. Böhm, and S. Paluch, "Service Robots: Drivers of Perceived Responsibility for Service Outcomes", Journal of Service Research, 22(4), 2019, pp. 404-420.

[17] Gursoy, D., O.H. Chi, L. Lu, and R. Nunkoo, "Consumers acceptance of artificially intelligent (AI) device use in service delivery", International Journal of Information Management, 49, 2019, pp. 157-169.

[18] Ling, E.C., I. Tussyadiah, A. Tuomi, J. Stienmetz, and A. Ioannou, "Factors influencing users' adoption and use of conversational agents: A systematic review", Psychology \& Marketing, 38(7), 2021, pp. 1031-1051.

[19] Benner, D., S. Schöbel, and A. Janson, "Exploring the State-of-the-Art of Persuasive Design for Smart Personal Assistants", in Proceedings of the 16th International Conference on Wirtschaftsinformatik, Duisburg-Essen, Germany, 2021.

[20] Lee, K.M., Y. Jung, J. Kim, and S.R. Kim, "Are physically embodied social agents better than disembodied social agents?: The effects of physical embodiment, tactile interaction, and people's loneliness in human-robot interaction", International Journal of Human-Computer Studies, 64(10), 2006, pp. 962-973.

[21] Seeger, A.-M., J. Pfeiffer, and A. Heinzl, "Designing Anthropomorphic Conversational Agents: Development and Empirical Evaluation of a Design Framework", in Proceedings of the International Conference on Information Systems, San Francisco, CA, USA, 2018.

[22] Qiu, L. and I. Benbasat, "Evaluating Anthropomorphic Product Recommendation Agents: A Social Relationship Perspective to Designing Information Systems", Journal of Management Information Systems, 25(4), 2009, pp. 145-182.

[23] McLean, G., K. Osei-Frimpong, and J. Barhorst, "Alexa, do voice assistants influence consumer brand engagement? Examining the role of AI powered voice assistants in influencing consumer brand engagement", Journal of Business Research, 124, 2021, pp. 312-328.

[24] Moriuchi, E., "Okay, Google!: An empirical study on voice assistants on consumer engagement and loyalty", Psychology \& Marketing, 36(5), 2019, pp. 489-501.

[25] Dabholkar, P.A. and B.I. Spaid, "Service failure and recovery in using technology-based self-service: effects on user attributions and satisfaction", The Service Industries Journal, 32(9), 2012, pp. 1415-1432.

[26] Smith, A.K., R.N. Bolton, and J. Wagner, "A Model of Customer Satisfaction with Service Encounters Involving Failure and Recovery", Journal of Marketing Research, 36(3), 1999, p. 356-372.
[27] Corti, K. and A. Gillespie, "Co-constructing intersubjectivity with artificial conversational agents: People are more likely to initiate repairs of misunderstandings with agents represented as human", Computers in Human Behavior, 58(5), 2016, pp. 431-442.

[28] Diederich, S., T.-B. Lembcke, A.B. Brendel, and L.M. Kolbe, "Understanding the Impact that Response Failure has on How Users Perceive Anthropomorphic Conversational Service Agents: Insights from an Online Experiment", AIS Transactions on Human-Computer Interaction, 13(1), 2021, pp. 82-103.

[29] Ho, T.H., D. Tojib, and Y. Tsarenko, "Human staff vs. service robot vs. fellow customer: Does it matter who helps your customer following a service failure incident?", International Journal of Hospitality Management, 87, 2020, 102501.

[30] Keaveney, S.M., "Customer Switching Behavior in Service Industries: An Exploratory Study", Journal of Marketing, 59(2), 1995, pp. 71-82.

[31] Poser, M., S. Singh, and E. Bittner, "Hybrid Service Recovery: Design for Seamless Inquiry Handovers between Conversational Agents and Human Service Agents", in Proceedings of the $54^{\text {th }}$ Hawaii International Conference on System Sciences, Hawaii, USA, 2021.

[32] Davidow, M., "Organizational Responses to Customer Complaints: What Works and What Doesn't", Journal of Service Research, 5(3), 2003, pp. 225-250.

[33] Wei, C., M.W. Liu, and H.T. Keh, "The road to consumer forgiveness is paved with money or apology? The roles of empathy and power in service recovery", Journal of Business Research, 118(2), 2020, pp. 321-334.

[34] Colquitt, J.A., "On the dimensionality of organizational justice: a construct validation of a measure", The Journal of applied psychology, 86(3), 2001, pp. 386-400.

[35] Kucherbaev, P., A. Bozzon, and G.-J. Houben, "HumanAided Bots", IEEE Internet Computing, 22(6), 2018, pp. 3643.

[36] Tsarenko, Y. and Y. Strizhakova, "Coping with service failures: The role of emotional intelligence, self-efficacy and intention to complain", European Journal of Marketing, 47(1/2), 2013, pp. 71-92.

[37] Weiner, B., "Attributional Thoughts about Consumer Behavior", Journal of Consumer Research, 27(3), 2000, pp. 382-387.

[38] Folkes, V.S., "Recent Attribution Research in Consumer Behavior: A Review and New Directions", Journal of Consumer Research, 14(4), 1988, pp. 548-565.

[39] Harris, K.E., L.A. Mohr, and K.L. Bernhardt, "Online service failure, consumer attributions and expectations", Journal of Services Marketing, 20(7), 2006, pp. 453-458.

[40] Hamilton, V.L., "Who is Responsible? Toward a Social Psychology of Responsibility Attribution", Social Psychology, 41(4), 1978, pp. 316-328. 
[41] Lei, X. and P.-L.P. Rau, "Effect of relative status on responsibility attributions in human-robot collaboration: Mediating role of sense of responsibility and moderating role of power distance orientation", Computers in Human Behavior, 122, 2021, 106820.

[42] Zhu, Z., C. Nakata, K. Sivakumar, and D. Grewal, "Fix It or Leave It? Customer Recovery from Self-service Technology Failures", Journal of Retailing, 89(1), 2013, pp. 15-29.

[43] Bradley, G.W., "Self-serving biases in the attribution process: A reexamination of the fact or fiction question", Journal of Personality and Social Psychology, 36(1), 1978, pp. 56-71.

[44] Moon, Y., "Don't Blame the Computer: When SelfDisclosure Moderates the Self-Serving Bias", Journal of Consumer Psychology, 13(1-2), 2003, pp. 125-137.

[45] Campbell, W.K. and C. Sedikides, "Self-Threat Magnifies the Self-Serving Bias: A Meta-Analytic Integration", Review of General Psychology, 3(1), 1999, pp. 23-43.

[46] Blut, M., C. Wang, N.V. Wünderlich, and C. Brock, "Understanding anthropomorphism in service provision: a meta-analysis of physical robots, chatbots, and other AI", Journal of the Academy of Marketing Science, 2021, pp. 127.

[47] Moon, Y. and C. Nass, "How "Real" Are Computer Personalities?", Communication Research, 23(6), 1996, pp. 651-674.

[48] Eyssel, F. and F. Hegel, "(S)he's Got the Look: Gender Stereotyping of Robots1", Journal of Applied Social Psychology, 42(9), 2012, pp. 2213-2230.

[49] Fiske, S.T., A.J.C. Cuddy, P. Glick, and J. Xu, "A model of (often mixed) stereotype content: Competence and warmth respectively follow from perceived status and competition", Journal of Personality and Social Psychology, 82(6), 2002, pp. 878-902.

[50] Cuddy, A.J., S.T. Fiske, and P. Glick, "Warmth and Competence as Universal Dimensions of Social Perception: The Stereotype Content Model and the BIAS Map", Advances in experimental social psychology, 40, 2008, pp. 61-149.

[51] Güntürkün, P., T. Haumann, and S. Mikolon, "Disentangling the Differential Roles of Warmth and Competence Judgments in Customer-Service Provider Relationships", Journal of Service Research, 23(4), 2020, pp. 476-503.

[52] Breazeal, C., "Toward sociable robots", Robotics and Autonomous Systems, 42(3-4), 2003, pp. 167-175.

[53] Judd, C.M., L. James-Hawkins, V. Yzerbyt, and Y. Kashima, "Fundamental dimensions of social judgment: understanding the relations between judgments of competence and warmth", Journal of Personality and Social Psychology, 89(6), 2005, pp. 899-913.
[54] Campbell, W.K., C. Sedikides, G.D. Reeder, and A.J. Elliot, "Among friends? An examination of friendship and the self-serving bias", British Journal of Social Psychology, 39(2), 2000, pp. 229-239.

[55] Lu, V.N., J. Wirtz, W.H. Kunz, S. Paluch, T. Gruber, A. Martins, and P.G. Patterson, "Service robots, customers and service employees: what can we learn from the academic literature and where are the gaps?", Journal of Service Theory and Practice, 30(3), 2020, pp. 361-391.

[56] Holland, J., L. Kingston, C. McCarthy, E. Armstrong, P. O'Dwyer, F. Merz, and M. McConnell, "Service Robots in the Healthcare Sector", Robotics, 10(1), 2021, p. 47.

[57] Bogue, R., "Robots in a contagious world", Industrial Robot, 47(5), 2020, pp. 673-642.

[58] Parekh, S. and J.C. Lim, "Receptivity \& Interaction of Social Robots in Hospitals", in Companion of the 2020 ACM/IEEE International Conference on Human-Robot Interaction (HRI '20 Companion), Cambridge, UK, 2020.

[59] Lastner, M.M., J.A.G. Folse, S.M. Mangus, and P. Fennell, "The road to recovery: Overcoming service failures through positive emotions", Journal of Business Research, 69(10), 2016, pp. 4278-4286.

[60] Russell, D., "The Causal Dimension Scale: A measure of how individuals perceive causes", Journal of Personality and Social Psychology, 42(6), 1982, pp. 1137-1145.

[61] Heerink, M., B. Kröse, V. Evers, and B. Wielinga, "Assessing Acceptance of Assistive Social Agent Technology by Older Adults: the Almere Model", International Journal of Social Robotics, 2(4), 2010, pp. 361-375.

[62] Bagozzi, R.P., D. Belanche, L.V. Casaló, and C. Flavián, "The Role of Anticipated Emotions in Purchase Intentions", Psychology \& Marketing, 33(8), 2016, pp. 629-645.

[63] Prahalad, C.K. and V. Ramaswamy, "Co-creation experiences: The next practice in value creation", Journal of Interactive Marketing, 18(3), 2004, pp. 5-14.

[64] Davison, R.M. and M.G. Martinsons, "Context is king! Considering particularism in research design and reporting", Journal of Information Technology, 31(3), 2016, pp. 241-249.

[65] van Vaerenbergh, Y., C. Orsingher, I. Vermeir, and B. Larivière, "A Meta-Analysis of Relationships Linking Service Failure Attributions to Customer Outcomes", Journal of Service Research, 17(4), 2014, pp. 381-398.

[66] Laranjo, L., A.G. Dunn, H.L. Tong, A.B. Kocaballi, J. Chen, R. Bashir, D. Surian, B. Gallego, F. Magrabi, A.Y.S. Lau, and E. Coiera, "Conversational agents in healthcare: a systematic review", Journal of the American Medical Informatics Association, 25(9), 2018, pp. 1248-1258.

[67] Aguinis, H. and K.J. Bradley, "Best Practice Recommendations for Designing and Implementing Experimental Vignette Methodology Studies", Organizational Research Methods, 17(4), 2014, pp. 351-371. 